08.1

\title{
Направленная самосборка микро- и нанопроводов оксида цинка
}

\author{
() И.А. Пронин ${ }^{1,2}$, И.А. Аверин ${ }^{1}$, Н.Д. Якушова ${ }^{1}$, А.А. Карманов ${ }^{1}$, В.А. Мошников ${ }^{1,2}$, Е.И. Теруков ${ }^{3}$ \\ ${ }^{1}$ Пензенский государственный университет, Пенза, Россия \\ ${ }^{2}$ Санкт-Петербургский государственный электротехнический университет „ЛЭтИ“, Санкт-Петербург, Россия \\ ${ }^{3}$ Физико-технический институт им. А.Ф. Иофффе РАН, Санкт-Петербург, Россия \\ E-mail: pronin_i90@mail.ru
}

Поступило в Редакцию 26 марта 2019г.

В окончательной редакции 26 марта 2019 г.

Принято к публикации 29 марта 2019г.

В рамках золь-гель-метода разработаны приемы направленной самосборки микро- и наностержней оксида цинка с использованием центробежной силы. Волокнистые структуры оксида цинка, предварительно полученные в золе, искусственно упорядочиваются на дальней периферии подложки при центрифугировании с высокими угловыми скоростями.

Ключевые слова: самосборка, оксид цинка, золь-гель-метод, центрифугирование.

DOI: 10.21883/PJTF.2019.12.47919.17806

Разработка высоковоспроизводимых методик синтеза полупроводниковых нанопроводов и наноремней с заданными и гибко настраиваемой ориентацией, и морфологией на различных подложках (моно-, поликристаллических, аморфных) является одной из ключевых проблем нанотехнологий, ограничивающей способность изготовления интегрированных наносистем, состоящих из различных материалов $[1,2]$. Для формирования высокоориентированных массивов наностержней и нанопроводов разработано множество способов, описанных в различных обзорах и монографиях [3-5]. В работе [6] продемонстрировано использование катализатора $\mathrm{Au}-\mathrm{Ni}$ для направленного роста нанопроводов $\mathrm{GaN}$ на подложке из оксида алюминия. Путем регулирования соотношения $\mathrm{Au}: \mathrm{Ni}$ авторы добились избирательного роста плотных однородных массивов $\mathrm{GaN}$ вдоль определенных направлений. В [7] для необходимой ориентации нанопроводов $\mathrm{ZnO}$ были использованы сапфировые подложки с различными кристаллографическими направлениями поверхности. Авторами было отмечено влияние ориентации нанопроводов на селективные и газочувствительные свойства оксида цинка к различным газам, а также предложена новая стратегия адаптации одномерных оксидных наноматериалов для сенсорных приложений. В [8] продемонстрирована методика контроля ориентации и геометрических свойств гидротермально выращенных нанопроводов $\mathrm{ZnO}$ посредством управления кристаллической текстурой и шероховатостью затравочного слоя $\mathrm{ZnO}$, полученного методом атомно-слоевого осаждения.

Среди методов направленной самосборки нанопроводов также можно выделить осаждение суспензий на подложки, содержащие рельефные поверхностные бороздки. При этом возможно получение высокоориентированных монослойных тонких пленок на макроскопических участках [9]. Аналогичные приемы ориентации хорошо известны из опыта задания ориентации нематических жидких кристаллов. Для технических приложений (сенсорика, оптоэлектроника и др.) развивается также метод „layer-by-layer“ $[10,11]$ - создание слоистых материалов с взаимно пересекающимися системами наноматериалов. В частности, использование такой сетевой системы серебряных нанопроводников позволяет улучшить качество верхних электродов для солнечных элементов по сравнению со случаем неупорядоченного расположения серебряных нанопроводов, образующих так называемые перколяционные прозрачные проводящие сети [12]. Следует отметить, что использование слоев с направленными нанообъектами технологически усложняет процесс изготовления приборов на их основе. При этом появляются дополнительные операции. Кроме того, между нанопроводами может возникать изолирующая прослойка.

Изготовление перколяционных сетей на основе направленных полупроводниковых нанообъектов представляет большой практический интерес с точки зрения создания сенсоров газа, однако имеются технологические сложности получения таких систем, находящихся на пороге протекания. Тем не менее в этих случаях возможно получение значений сенсорного отклика, превышающих на несколько порядков газочувствительность адсорбционных полупроводниковых датчиков, полученных традиционными методами $[13,14]$. Эффект связан с тем, что электрически активный адсорбированный кислород (на ветвях с толщиной менее удвоенной длины экранирования Дебая) блокирует пути протекания электронов и электрическое сопротивление структуры может быть очень большим. При появлении восстанавливающих газов происходит десорбция продуктов их реакции с кислородом с возвращением электрона в зону проводимости. В результате возникают дополнительные пути протекания, проводимость возрастает и значения сенсорного отклика увеличиваются вплоть до $10^{5}-10^{6}$. 


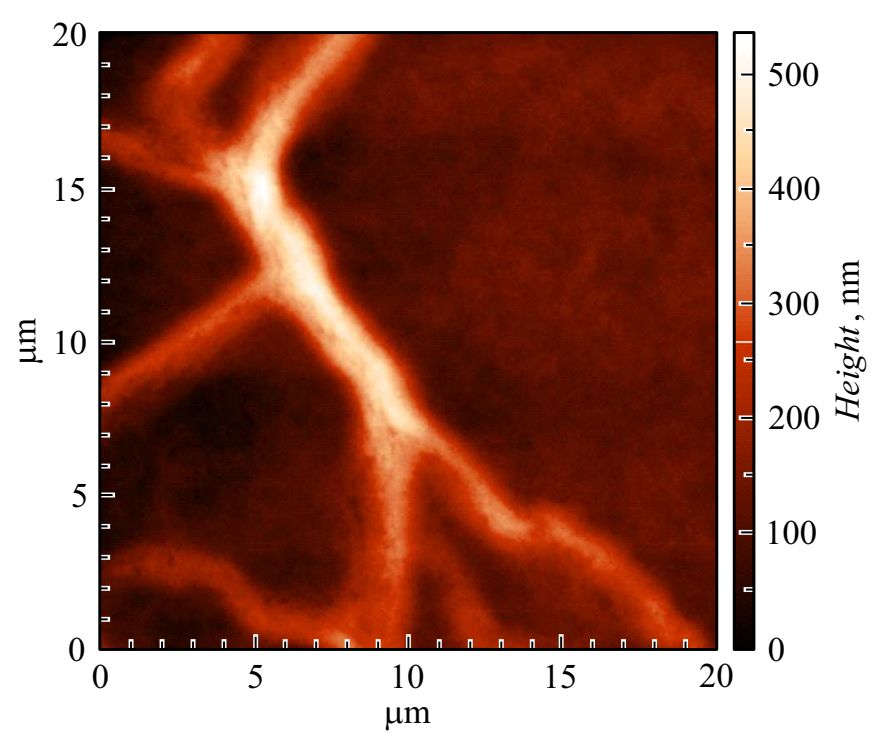

Рис. 1. Структура композитных слоев на основе нано- и микростержней $\mathrm{ZnO}$.

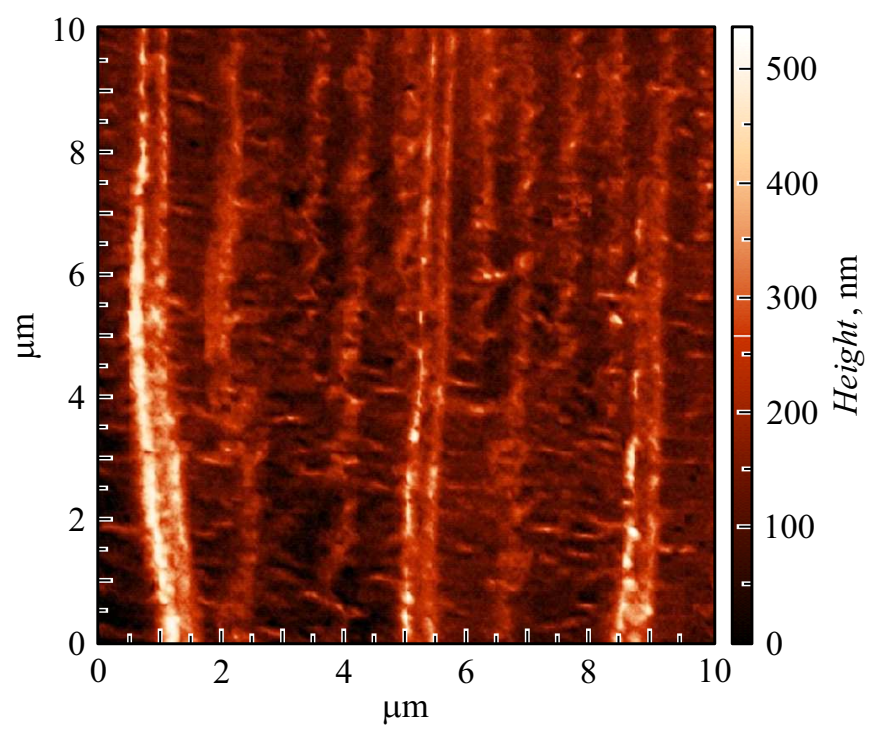

Рис. 2. Направленная самосборка микро- и нанопроводов оксида цинка на периферии подложки.

Сложность реализации перколяционных сетей заключается в том, что порог протекания даже в идеальных решетчатых задачах является заданным числом только для бесконечной решетки. Это легко понять, если из существующего перколяционного кластера вырезать ограниченные решетки, одни из которых по определению могут обладать высокой проводимостью, а в других может отсутствовать протекание. Поэтому для развития технологии создания перколяционных сетей чрезвычайно важным является получение ,полуфабрикатов“ из системы взаимно пересекающихся упорядоченных массивов одномерных объектов, причем желательно, чтобы верхний слой состоял из объектов с толщинами ветвей протекания, соизмеримыми с дебаевской длиной экранирования. Такая система обладает анизотропией проводимости: вертикально направленные нанообъекты даже при адсорбции электрически активного кислорода сохраняют проводимость и могут быть использованы в качестве одномерных электродов для снятия информации. Поперечные нанообъекты, напротив, представляют интерес для изучения и регистрации особенностей адсорбции молекул газа. Наличие системы электродов представляет интерес для изучения особенностей поведения перколяционных сетей при получении зависимостей электропроводности с различных электродов. При этом также возможна подстройка рассматриваемых микро- и наносистем под условия, оптимальные для чувствительности сенсора к заданному содержанию детектируемого газа. Иными словами, возможно искусственно прерывать ветви низких уровней иерархии.

Среди методов управления ориентацией нанопроводов способ с использованием центробежной силы привлекает своей простотой, дешевизной и воспроизводимостью. При этом на подложке, подвергнутой центрифугированию, на периферии возможно получение высокоупорядоченных массивов одномерных микро- и нанообъектов. В наших предыдущих работах [4,5] были рассмотрены приемы литографической самосборки коллоидных наночастиц для развития фрактальной нанолитографии, а также показана принципиальная возможность формирования литографических рисунков, первичными элементами которых являются ограненные микрокристаллы.

Настоящая работа является развитием разработанных нами подходов и показывает возможность упорядочения массивов микро- и нанопроводов с помощью центробежной силы.

В работе приводятся полученные нами результаты по созданию системы параллельно направленных микро- и нанопроводов оксида цинка, на базе которых возможно создавать сенсоры различного функционального назначения, матрицы мемристоров и дисплеев, катализаторы и т.д. Например, использование полупроводниковых волокон в качестве обкладок конденсаторов позволит получить емкостные сенсоры углекислого газа. Нанесение на полученную систему квантовых точек откроет возможность синтеза интегрированных наносистем с уникальными каталитическими и фотокаталитическими свойствами.

Для получения высокоориентированных микро- и нанопроводов оксида цинка был использован золь-гель-метод $[15,16]$. Для этого в качестве прекурсоров были выбраны двухводный ацетат цинка, 2-аминоэтанол и 2-метоксиэтанол. Все вещества смешивались в круглодонной колбе, выдерживались при $80^{\circ} \mathrm{C}$ в течение $1 \mathrm{~h}$, после чего полученная смесь созревала $24 \mathrm{~h}$ при комнатной температуре. На ранних этапах созревания золей за счет реакций гидролитической поликонденса- 
ции формировались ядра оксида цинка согласно схемам

$$
\begin{aligned}
\left(\mathrm{CH}_{3} \mathrm{COO}\right)_{2} \mathrm{Zn} & +\mathrm{H}_{2} \mathrm{O} \Leftrightarrow \mathrm{ZnOH}\left(\mathrm{CH}_{3} \mathrm{COO}\right) \\
& +\mathrm{CH}_{3} \mathrm{COOH}, \\
2 \mathrm{ZnOH}\left(\mathrm{CH}_{3} \mathrm{COO}\right) \Leftrightarrow & \mathrm{CH}_{3} \mathrm{COO}-\mathrm{Zn}-\mathrm{O}-\mathrm{Zn}-\mathrm{CH}_{3} \mathrm{COO} \\
& +\mathrm{H}_{2} \mathrm{O} .
\end{aligned}
$$

Эти реакции протекают относительно медленно из-за низкой концентрации воды, вводимой в процессы синтеза из кристаллогидрата $\left(\mathrm{CH}_{3} \mathrm{COO}\right)_{2} \mathrm{Zn} \cdot 2 \mathrm{H}_{2} \mathrm{O}$, т.е. $\left[\mathrm{H}_{2} \mathrm{O}\right] /\left[\mathrm{Zn}^{2+}\right]=2$. Введение в реакционную смесь 2-аминоэтанола, выступающего в качестве комплексообразующего агента, также задерживает конденсацию $\mathrm{Zn}(\mathrm{II})$, однако присутствие этого амина, являющегося слабым основанием, смещает $\mathrm{pH}$ раствора в щелочную сторону, что способствует образованию $\mathrm{ZnO}$. Присутствие ацетат-иона также играет большую роль в образовании комплекса $\mathrm{c} \mathrm{Zn}^{2+}$, которое протекает в конкуренции с процессом комплексообразования с 2-аминоэтанолом. В целом три нуклеофила (2-аминоэтанол, $\mathrm{CH}_{3} \mathrm{COO}^{-}$, $\mathrm{OH}^{-}$) конкурируют за образование комплекса с $\mathrm{Zn}^{2+}$. Наличие $\mathrm{OH}^{-}$приводит к образованию смеси олигомеров оксоацетатов цинка. Один из возможных видов процесса, связанный с образованием оксоацетатов цинка, можно для примера схематически отразить следующим уравнением [17]:

$$
\begin{gathered}
5\left(\mathrm{CH}_{3} \mathrm{COO}\right)_{2} \mathrm{Zn} \cdot 2 \mathrm{H}_{2} \mathrm{O} \Leftrightarrow \mathrm{Zn}_{5}(\mathrm{OH})_{8}\left(\mathrm{CH}_{3} \mathrm{COO}\right)_{2} \cdot 2 \mathrm{H}_{2} \mathrm{O} \\
+8 \mathrm{CH}_{3} \mathrm{COOH}
\end{gathered}
$$

номинально он не требует дополнительной воды. В золях на начальных этапах их созревания формирование молекулярных кластеров происходит на основе следующих соединений: $\mathrm{Zn}_{10} \mathrm{O}_{4}\left(\mathrm{CH}_{3} \mathrm{COO}\right)_{12}, \mathrm{Zn}_{4} \mathrm{O}\left(\mathrm{CH}_{3} \mathrm{COO}\right)_{6}$, $\mathrm{Zn}_{5}(\mathrm{OH})_{8}\left(\mathrm{CH}_{3} \mathrm{COO}\right)_{2} \cdot 2 \mathrm{H}_{2} \mathrm{O}$ [18]. Конденсация продуктов гидролиза приводит к формированию коллоидных растворов на основе частиц оксида цинка с прикрепленными к поверхности ацетатными лигандами.

На поздних этапах созревания золей полученные коллоидные частицы оксида цинка претерпевают агрегацию, причем данный процесс может протекать вплоть до образования перколяционного стягивающего кластера, когда все агрегаты закрепляются на одном остове и происходит переход золь-гель. Однако данный процесс наблюдается не всегда из-за явления спинодального распада. При этом материал приобретает волокнистую иерархическую структуру, сформированную из доперколяционных фрагментов, заключенных в лабиринтную сетку.

На рис. 1 представлена типичная сетчатая структура композитных слоев на основе нано- и микростержней $\mathrm{ZnO}$, синтезированных из полученного золя методом центрифугирования при $1000 \mathrm{rpm}$ в течение $1 \mathrm{~min}$ и отожженных в воздушной атмосфере при $600^{\circ} \mathrm{C}$ в течение $1 \mathrm{~h}$. Изображение получено с помощью атомносиловой микроскопии. Видно, что образец имеет ветвистую структуру со средним диаметром $1-2 \mu \mathrm{m}$, при этом какого-либо упорядоченного расположения данных проводов по поверхности не наблюдается.

Для ориентации полученных микро- и нанопроводов в выбранном направлении по поверхности подложки нами было предложено использовать центробежную силу. При этом в качестве подложек использовались предметные стекла (размер $25 \times 75 \mathrm{~mm}$ ), а скорость вращения центрифуги составляла $4000 \mathrm{rpm}$. В центре подложки, а также в областях, удаленных от центра на расстояние, не превышающее $30 \mathrm{~mm}$, структура поверхности пленок после отжига повторяла структуру, представленную на рис. 1. Однако на дальней периферии подложек, отдаленной от центра на расстояния более $30 \mathrm{~mm}$, происходило упорядочение микро- и нановолокон вдоль радиуса вращения (рис. 2). Для усиления отмеченной тенденции формирования первичного слоя композита целесообразно создавать на подложке систему штриховых канавок, направленных к центру. Образующийся верхний слой содержит систему боковых связей, формирующих газочувствительную сеть наностержней с перколяционной структурой.

Таким образом, нами разработаны простые приемы упорядочения нано- и микропроводов оксида цинка, полученных в рамках золь-гель-метода, с помощью центробежной силы при центрифугировании. Полученные результаты имеют актуальность при получении упорядоченных стержней других металлооксидных полупроводников.

\section{Финансирование работы}

Работа выполнялась при финансовой поддержке Министерства образования и науки РФ (проект № 16.897.2017/ПЧ), гранта Президента РФ для молодых кандидатов наук (МК-1882.2018.8) и стипендии Президента РФ (СП-84.2018.1).

\section{Конфоликт интересов}

Авторы заявляют, что у них нет конфликта интересов.

\section{Список литературы}

[1] Dasgupta N.P., Sun J., Liu C., Brittman S., Andrews S.C., Lim J., Gao H., Yan R., Yang P. // Adv. Mater. 2014. V. 26. N 14. P. 2137-2184. DOI: 10.1002/adma.201305929

[2] Pan Z.W., Dai Z.R., Wang Z.L. // Science. 2001. V. 291. N 5510. P. 1947-1949. DOI: $10.1126 /$ science. 1058120

[3] Ozin G.A., Hou K., Lotsch B.V., Cademartiri L., Puzzo D.P., Scotognella F., Ghadimi A., Thomson J. // Mater. Today. 2009. V. 12. N 5. P. 12-23. DOI: 10.1016/S1369-7021(09)70156-7

[4] Бобков А.А., Пронин И.А., Мочников В.А., Якушова Н.Д., Карманов А.А., Аверин И.А., Сомов П.А., Теруков Е.И. // Письма в ЖТФ. 2018. Т. 44. В. 15. С. 87-92. 
[5] Мочников В.А., Максимов А.И., Александрова О.А., Пронин И.А., Карманов А.А., Теруков Е.И., Якушова Н.Д., Аверин И.А., Бобков А.А., Пермяков Н.В. // Письма в ЖТФ. 2016. Т. 42. В. 18. С. 81-87.

[6] Kuykendall T.R., Altoe M.V.P., Ogletree D.F., Aloni S. // Nano Lett. 2014. V. 14. N 12. P. 6767-6773.

DOI: $10.1021 / \mathrm{n} 1502079 \mathrm{v}$

[7] Roso S., Güell F., Martínez-Alanis P.R., Urakawa A., Llobet E. // Sensors Actuators B. 2016. V. 230. P. 109-114. DOI: $10.1016 /$ j.snb.2016.02.048

[8] Bielinski A.R., Kazyak E., Schlepütz C.M., Jung H.J., Wood K.N., Dasgupta N.P. // Chem. Mater. 2015. V. 27. N 13. P. 4799-4807. DOI: 10.1021/acs.chemmater.5b01624

[9] Probst P.T., Sekar S., König T.A., Formanek P., Decher G., Fery A., Pauly M. // ACS Appl. Mater. Int. 2018. V. 10. N 3. P. 3046-3057. DOI: 10.1021/acsami.7b15042

[10] Richardson J.J., Cui J., Bjornmalm M., Braunger J.A., Ejima H., Caruso F. // Chem. Rev. 2016. V. 116. N 23. P. 14828-14867. DOI: 10.1021/acs.chemrev.6b00627

[11] Tebbe M., Mayer M., Glatz B.A., Hanske C., Probst P.T., Müller M.B., Karg M., Chanana M., König T.A.F., Kuttner C., Fery A. // Faraday Discussions. 2015. V. 181. P. 243-260. DOI: $10.1039 / \mathrm{C} 4 \mathrm{FD} 00236 \mathrm{~A}$

[12] Wu F., Li Z., Ye F., Zhao X., Zhang T., Yang X. // J. Mater. Chem. C. 2016. V. 4. N 47. P. 11074-11080. DOI: $10.1039 / \mathrm{C} 6 \mathrm{TC} 03671 \mathrm{~F}$

[13] Крастева Л.К., Димитров Д.Ц., Папазова К.И., Николаев Н.К., Пешкова Т.В., Мошников В.А., Грачева И.Е., Карпова С.С., Канева Н.В. // ФТП. 2013. Т. 47. В. 4. С. 564 569.

[14] Мочников В.А., Налимова С.С., Селезнев Б.И. // ФТП. 2014. T. 48. B. 11. C. 1535-1539.

[15] Dimitrov D.Tz., Nikolaev N.K., Papazova K.I., Krasteva L.K., Pronin I.A., Averin I.A., Bojinova A.S., Georgieva A.Ts., Yakushova N.D., Peshkova T.V., Karmanov A.A., Kaneva N.V., Moshnikov V.A. // Appl. Surf. Sci. 2017. V. 392. P. 95-108. DOI: 10.1016/j.apsusc.2016.08.049

[16] Пронин И.А., Аверин И.А., Божсинова А.С., Георгиева А.Ц., Димитров Д.Ц., Карманов А.А., Мошников В.А., Папазова К.И., Теруков Е.И., Якушова Н.Д. // Письма в ЖТФ. 2015. Т. 41. В. 19. С. 23-29.

[17] Hosono E., Fujihara S., Kimura T., Imai H. // J. Coll. Interf. Sci. 2004. V. 272. N 2. P. 391-398. DOI: $10.1016 /$ j.jcis.2003.10.005

[18] Hosono E., Fujihara S., Kimura T., Imai H. // J. Sol-Gel Sci. Technol. 2004. V. 29. N 2. P. 71-79.

DOI: 10.1023/B:JSST.0000023008.14883.1e 